\title{
DOSSIÊ
}

\section{Violência e meios de comunicação de massa na sociedade contemporânea}

MARIA STELA GROSSI PORTO*

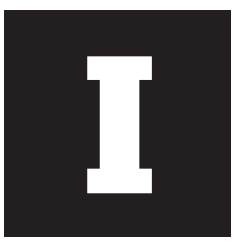

nicio comentando, de modo muito breve, o sentido dos termos que dão título ao presente texto.

Dos três, o que diz respeito à violência é, em minha avaliação, o que acarreta mais problemas de definição. Começando então por ele, gostaria de salientar que partiIho o conceito elaborado por Yves Michaud para quem

há violência quando, numa situação de interação um ou vários atores agem de maneira direta ou indireta, maciça ou esparsa, causando danos a uma ou mais pessoas em graus variáveis, seja em sua integridade física, seja em sua integridade moral, em suas posses, ou em suas participaçôes simbólicas e culturais (Michaud, Y, 1989, p. 11).

Esse conceito, de natureza operacional, não chega a ser totalmente isento de ambigüidades, sendo a primeira delas a imprecisão sobre a intencionalidade ou não do agente. Será a intencionalidade do ato condição sine qua non para a existência de violência? Será a premeditação um requerimento para a existência de intencionalidade? A definição não chega a esclarecer totalmente essas dúvidas. Embora se possa admitir que sim, que estes seriam requerimentos necessários para que se possa concluir 
pelo caráter violento de uma dada ação, não se pode deixar de considerar as muitas circunstâncias em que atos com desfechos violentos e com danos reais a uma ou mais pessoas possam ser incluídos no rol dos chamados resultados não previstos da ação, com os quais a análise sociológica é freqüentemente confrontada, potencializando a complexidade da questão da causalidade.

A dificuldade conceitual, que de modo algum é prerrogativa da definição proposta por Michaud, decorre de várias razões, entre as quais mencionaria, como um primeiro aspecto, o fato de a violência ser um fenômeno empírico antes do que um conceito teórico. Retirado diretamente da realidade social que descreve, o conceito tem sido de tal forma apropriado pelo senso comum, pela política, pela mídia ou por vários outros campos que não o científico, que sua reapropriação acadêmica carece de uma explicitação dos sentidos nos quais é utilizado. Faz-se necessário, em outras palavras, que o fenômeno da violência seja construído como objeto teórico, de modo a que sua utilização, no interior do discurso científico, adquira força explicativa e sentido.

Apesar das imprecisões apontadas, o conceito proposto por Michaud tem a vantagem de permitir uma abordagem da violência a partir das diferentes dimensões que constituem a vida social, aí compreendidas as dimensões material e simbólica, sendo esta última compatível com as abordagens que abrem espaço para a variabilidade histórico-cultural.

A partir desta perspectiva, é possível considerar que aquilo que, em um dado momento, numa dada sociedade, é considerado como violência varia segundo a natureza da sociedade considerada, configurando a realidade empírica da violência como um fenômeno polissêmico e plural. A rigor, não faz sentido falar em violência no singular, já que estamos confrontados com manifestações plurais de violência, cujas raízes e efeitos, igualmente múltiplos, apontam a existência de tipos diferenciados de violência, realidade que remete à necessidade de pensar a violência a partir de suas relações com a cultura. 
A constatação destas relações intrínsecas entre violência e cultura evidenciaria um segundo aspecto da dificuldade conceitual já mencionada: se do ponto de vista teórico - conceitual a polissemia e a pluralidade referidas não podem ser sinônimos de adesão ao credo relativista, cuja exarcebação leva ao irracionalismo que, no limite, inviabiliza a atividade científica, do ponto de vista empírico, a ênfase posta na cultura e nas especificidades próprias a toda e qualquer sociedade exige um olhar que considere a relatividade valorativa presente nas distintas culturas e que implica necessariamente distintas representações da violência, as quais cabe ao sociólogo tomar como objeto de análise, caso tenha pretensões à elaboração de uma sociologia ou teoria da violência.

As mudanças recentes vivenciadas pela sociedade brasileira têm contribuído para uma ressignificação da violência, no sentido de não aceitar eufemismos para defini-la e de nomear como violência atos e comportamentos que eram, há até bem pouco tempo, considerados formas ou conteúdos corriqueiros de regulamentação social. Ao ser pensada pelo viés da violência, a sociedade brasileira se tem revelado mais exigente, mais organizada e pronta a reivindicar o fim da impunidade e a vigência de padrões mais solidários de relações e interações sociais. Em contrapartida às reiteradas manifestações de violência, tem havido crescente mobilização da sociedade civil em prol da não-violência e, portanto, da paz.

Esse é um aspecto da questão. Lado a lado com ele há um outro, cujas implicações não terei como aprofundar no âmbito deste texto, mas que importa, pelo menos, mencionar; aponta para o conteúdo hierárquico e desigual que marca, de um modo geral, as relações sociais na sociedade brasileira, traço cultural cujas conseqüências significativas não podem ser descartadas, quando o que está em pauta é a busca de compreensão para a realidade da violência presente no dia-a-dia da vida social.

Continuando o que estou considerando "comentários de natureza conceitual", para efeitos dos argumentos desenvolvidos a seguir, proporia 
pensar o conceito de meios de comunicação de massa à luz das novas tecnologias de comunicação e de informação que, pela radicalidade das transformações que introduziram no cotidiano de milhões e milhões de pessoas, configuram, como pretendo analisar no decorrer deste texto, uma verdadeira revolução científico-tecnológica.

Com relação ao conceito de contemporaneidade, admito estar utilizando-o para dar conta de situações que muitos estudiosos têm abordado a partir da ótica, tão em voga, da pós-modernidade, em relação à qual, entretanto, confesso sentir um certo incômodo.

A relativa imprecisão que acompanha o conceito de pós-modernidade, levando a que dificilmente duas pessoas estejam reportando-se exatamente aos mesmos conteúdos teóricos ou empíricos quando se referem às sociedades pós-modernas, não chega a ser, por si só, um empecilho à sua utilização, embora demande um cuidado maior em termos de possíveis análises comparativas. O que me leva a evitá-lo, quando posso, é o fato de sua utilização significar, na prática, que se considera a modernidade encerrada ou ultrapassada, enquanto período histórico e conceito. Não compartilho esse ponto de vista preferindo, ao contrário, as análises que afirmam não terem as atuais sociedades atingido alguns dos grandes ideais da modernidade, a partir dos quais o lluminismo inspirou os revolucionários de 1789, e continua ainda a inspirar outros tantos projetos societários, independentemente da multiplicidade de análises, nada consensuais, dedicadas à filosofia e ao ideário iluminista.

Se o conteúdo mais significativo do conceito de pós-modernidade parece ser o da fragmentação de valores, da ausência de homogeneidade e da perda de sentido, então, a rigor, ele não é incompatível com o conceito de contemporaneidade. Este último tem conseguido exprimir com clareza a natureza e a radicalidade das mudanças vivenciadas pelas sociedades hoje, as quais combinam e articulam um processo no qual globalização, enquanto tendência, e fragmentação/diversificação enquanto espaço 
empírico de realização da tendência, podem constituir de fato um único processo que é, a um só tempo, econômico e sociocultural.

Considerando a revolução científico-tecnológica como uma das marcas da modernidade contemporânea, o presente texto encaminha a reflexão a partir de dois registros interligados: o primeiro, de natureza mais teórica, busca as relações que as transformações decorrentes da revolução científico-tecnológica do mundo contemporâneo (aí compreendidos os meios de massa) estabeleceriam com a violência. O segundo, concentra a argumentação em resultados da pesquisa As Representações Sociais da Violência no Distrito Federa/ (pesquisa coordenada pela autora no âmbito do Plano Piloto e das Cidades Satélites de Brasília). Para este texto, foram selecionados apenas os conteúdos ligados à mídia. No âmbito dessa pesquisa, foram aplicados 625 questionários, a partir de uma amostra proporcional no que diz respeito às categorias de sexo e idade, enquanto variáveis de identificação, e aleatória no tocante às categorias socioeconômicas, de escolaridade, de residência, de situação profissional, de etnia e de religião. Trabalhando com uma margem de erro de 4\%, chegou-se à população pesquisada através de sorteio, utilizando-se o código de Endereçamento Postal - CEPs, como garantia de inclusão de todas as regiões administrativas do DF. O questionário foi organizado em sete blocos de perguntas, centrados nos seguintes conteúdos: Violência e Cordialidade; Violência e Legitimidade; Violência e Direitos; Violência e Instituições; Violência e Pobreza; Violência e Justiça; Violência e Mídia. Utilizaram-se apenas perguntas fechadas, estruturadas através de ditados populares, provérbios, afirmações do senso comum, ideologias, crenças, chavões, como forma de captar a racionalidade presente no imaginário popular e submetê-la ao crivo da ciência.

A esse respeito, gostaria de ressaltar alguns pressupostos da utilização das representações sociais enquanto estratégia metodológica de aproximação da realidade. In-terrogar a realidade a partir do que se diz sobre ela, utilizando-se a categoria de representações sociais, significa assumir que 
(a) embora resultado da experiência individual, as representações sociais são condicionadas pelo tipo de inserção social dos indivíduos e dos grupos de indivíduos que as produzem; (b) expressam visões de mundo objetivando explicar e dar sentido aos fenômenos dos quais se ocupam, ao mesmo tempo em que, por sua condição de representação social, participam também da constituição desses mesmos fenômenos; (c) em decorrência, no exposto em " $b$ " apresentam-se como máximas orientadoras de condutas; d) que existe conexão de sentido entre os fenômenos e suas representações sociais que, portanto, não são nem falsas nem verdadeiras, mas a matéria prima do fazer sociológico.

Explicitando os pressupostos teóricos que orientam a reflexão, gostaria de argumentar que as mudanças que atravessam o conjunto da sociedade brasileira, desenvolvem- se no contexto de transformações que são mundiais e inserem reflexões de caráter nacional no movimento mais geral dessas transformações, pensadas a um só tempo enquanto propulsoras e resultantes do processo de globalização.

A globalização assume estatuto de categoria articuladora do pensamento e da análise, a indicar a dimensão das mudanças, sem implicar, no entanto, a identificação entre globalização e homogeneização. Se é pertinente supor que a revolução científico-tecnológica atinge o âmbito planetário, as formas através das quais este movimento se realiza encontram, todavia, configurações sociais as mais diferenciadas, levando a definições e redefinições do espaço sociocultural igualmente diferenciadas.

É possível pensar a relação entre tais transformações e a questão da violência, a partir de duas vertentes distintas, mas interligadas, de reflexão. A primeira delas parte das transformações que afetam o conjunto da sociedade, como decorrência das mudanças que a atual revolução científico tecnológica vêm efetivando sobretudo no mundo do trabalho, e cuja direção tem apontado para sua superação enquanto componente hegemônico de organização e de estruturação das relações sociais. Os processos de transformação pelos quais vem passando o trabalho afetam sua característica de 
integração social, com uma configuração fundamentalmente marcada pela fragmentação. Não só mudam as características do trabalho como muda a forma como é representado por amplas camadas da população.

Em um mundo 'regido' pelo trabalho, as classes sociais podiam, em alguma medida, ser pensadas como categorias 'unificadoras' do social. As mudanças tecnológicas, ao incidirem diretamente sobre o mundo do trabalho, deslocando seu caráter e centralidade enquanto organizador de um ambiente sociocultural, transformam a natureza desse social e afetam igualmente o trabalho em suas dimensões simbólica, ideológica, e valorativa Enquanto valor, o trabalho era responsável, não tanto pela unidade do social mas por sua representação como algo unificado. Atualmente, as transformações desse universo e o deslocamento dos valores nele centrados, evidenciam o surgimento de um social atomizado, fragmentado, carente de pontos fixos de referência (Porto, 2000).

A argumentação para subsidiar a presente reflexão vai na mesma direção. Estamos em presença de um social heterogêneo, no qual nem indivíduos nem grupos parecem reconhecer valores coletivos. Este contexto dá origem a múltiplos arranjos societários, a múltiplas lógicas de condutas. Predominando tal situação, é válido falar em sociedade fragmentada, plural, diferenciada, heterogênea, tanto no âmbito material - das organizações e dos movimentos sociais - quanto no simbólico, no qual diferentes sistemas de valores vivem e convivem de forma mais ou menos autônoma, numa espécie de "contigüidade", para usar uma noção empregada por Machado (1997, p. 16). Sociedades nas quais prevalecem tais situações são passíveis de múltiplas lógicas de ação, organização e reorganização do espaço social e de múltiplos recursos de atuação, entre os quais figura, ou pode figurar, o da violência. 
Se os argumentos adiantados têm validade, pode-se afirmar que a fragmentação não só se constitui em categoria chave para pensar a sociedade brasileira como, além disso, ela é igualmente pertinente para dar conta das formas como essa sociedade se representa. Pensada como uma situação de fragmentação valorativa, a contemporaneidade brasileira se vê também confrontada pelas conseqüências dessa fragmentação no plano simbólico e por um contexto de grandes desigualdades no plano material, as quais, reflexivamente, alimentam a fragmentação e a pluralidaddes dos valores. Violência real e representação da violência como forma de manifestação de exclusão simbólica e material são fenômenos interdependentes e se constituem em fatores orientadores da ação (ou da sua ausência).

A fragmentação enquanto forma de estruturação social distancia a análise sociológica do conceito de socialização, consoante contextos sociais relativamente homogêneos, nos quais a maioria dos indivíduos compartilha conteúdos e valores básicos de uma consciência coletiva. Registra, ao invés, a existência de novas sociabilidades, no plural, situação mais condizente com as novas possibilidades de estruturação social. Tal realidade sugere que as sociedades contemporâneas não comportam um processo de socialização, mas produzem, e são produzidas por distintas formas de sociabilidades que, no mais das vezes, dizem respeito a grupos, camadas, etnias e raças, não tendo, pois, vigência no conjunto da sociedade.

É assim que se pode falar em novas sociabilidades decorrentes dos processos de transformação em curso. Sociabilidades que se estruturam em razão da existência de solidariedades, mas também a partir e em função de sua ausência. É o caso de sociabilidades estruturadas na e pela violência, quase que como resposta a carências, ausências, falhas, rupturas, aspectos que são, todos eles, frutos da explosão de múltiplas lógicas de ação, recurso disponível no rol de muitos outros possíveis. Estes aspectos são vivenciados como características e condições da sociedade contemporânea, que envolve risco e insegurança, implícita ou explicitamente presentes nas representações sociais aqui abordadas. 
Os meios de massa, se não são diretamente responsáveis pelo aumento da violência e da criminalidade, seriam, quando menos, um canal de estruturação de sociabilidades violentas, já que aí a violência é, não raro, apresentada como um comportamento valorizado. Ou ainda, recorrendo a um outro texto de Michaud (1996, p. 136),

a violência, na mídia, seja ela estilizada ou não, seja ficção ou parte dos telejornais da atualidade serve, de uma certa maneira, a um descarregar-se, distender-se, dar livre curso aos sentimentos através do espetáculo. As cenas de violência são um sintoma da 'nervosidade' da sociedade.

Podem não tornar as crianças mais violentas, mas certamente contribuem para excitá-las. Além do que, afirma Michaud,

estudos recentes reconhecem, em laboratório, uma correlação entre observação da violência e agressão. Os estudos em meio real são menos significativos. Mas não há dúvida de que as imagens da violência contribuem de modo não desprezível para mostrá-la como mais normal, menos terrivel do que ela é, em suma: banal, criando, assim, um hiato entre a experiência anestesiada e as provas da realidade, raras, mas muito mais fortes (1989, p. 51).

$\mathrm{Na}$ condição de recurso, a violência se insere em um elenco de estratégias, sua utilização passa a ser questão de eficácia, oportunidade, afirmação de identidades socialmente negadas, explosão de raivas, frustrações, dentre tantas outras possibilidades, com implicações diretas nas formas de representação social do fenômeno. Não apenas as novas sociabilidades se estruturam na violência, como pode a própria violência ser o conteúdo e o substrato das representações sociais.

Sob este aspecto, as representações elaboradas pelos respondentes da pesquisa acima mencionada são um pouco mais diretas e, talvez, menos 
sofisticadas do que reflexões que a literatura oferece: estabelecem uma relação causal direta entre exposição à violência e aumento da criminalidade; 78 , 6\% dos respondentes acreditam que a difusão da violência pela mídia contribuiria para aumentar a criminalidade.

Gráfico 1. "A difusão da violência nos meios de comunicação pode contribuir para o aumento da criminalidade social?"

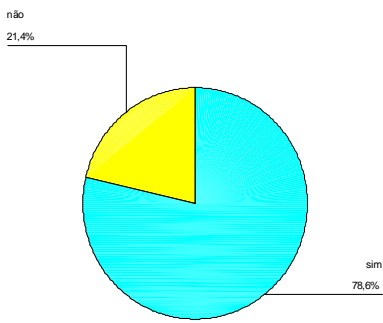

Aqui percebe-se uma distinção por faixa etária, os jovens revelando mais condescendência com a mídia, em relação ao potencial indutor de violência. Aliás, são várias as respostas ao questionário, indicando que as representações dos jovens são mais propensas a acatar manifestações de violência do que as das demais faixas etárias. Assim, entre os jovens, 26,0\% não relacionam exposição à violência na mídia e aumento de criminalidade, contra $19,0 \%$ e $17,0 \%$ respectivamente, das demais faixas de idade, ou seja, entre 25 e 44 anos e mais de 45 anos.

Afora isso, no geral há uma condenação da mídia, tendência que parece solidária àquela de diabolizar seu papel, minimizando o fato de que o consumo desses meios alimenta os conteúdos servidos. 
Tabela 1.

\begin{tabular}{|c|c|c|c|c|}
\hline & \multicolumn{2}{|c|}{$\begin{array}{l}\text { "A difusão da violência nos meios de } \\
\text { comunicação po de contribuir para o } \\
\text { aumento da criminalidade social?" }\end{array}$} & \multirow[b]{2}{*}{ Total } \\
\hline & & $\operatorname{sim}$ & não & \\
\hline \multirow[t]{3}{*}{ Tdade } & 15 a 24 & $74,0 \%$ & $26,0 \%$ & $100,0 \%$ \\
\hline & 25 a 44 & $80,1 \%$ & $19,9 \%$ & $100,0 \%$ \\
\hline & acima de 45 & $82,6 \%$ & $17,4 \%$ & $100,0 \%$ \\
\hline Total & & $78,6 \%$ & $21,4 \%$ & $100,0 \%$ \\
\hline
\end{tabular}

Fonte: Pesquisa sobre Representações Sociais da Violência no DF, 1998.

Tabela 2 .



Fonte: Pesquisa sobre Representações Sociais da Violência no DF, 1998.

Tabela 3.

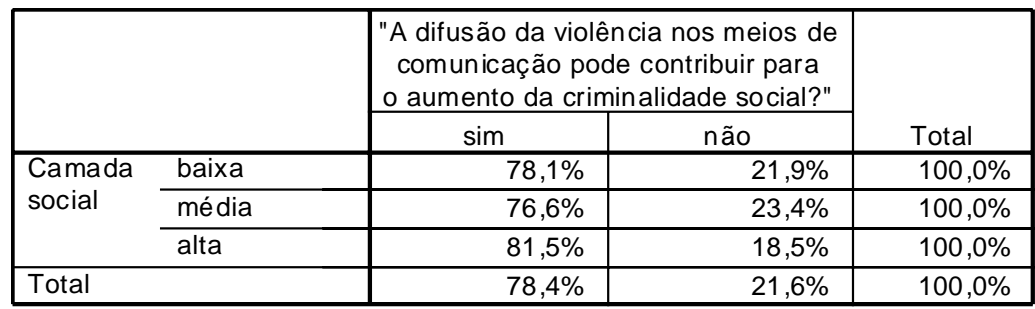

Fonte: Pesquisa sobre Representações Sociais da Violência no DF, 1998. 
A radicalidade e a abrangência que caracterizam a revolução científico-tecnológica são, elas mesmas, uma forma de violência, na medida em que rompem, redefinem, deslocam ou superam o mundo tradicional e os processos de organização social por ele informados, afetando a sociedade em múltiplos aspectos e em diferentes esferas, operando uma transformação na natureza social. Por exemplo, ao pensar as repercussões deste processo na dimensão cultural da vida social, pode-se dizer que, no tocante aos processos de informação, o Brasil mergulhou na era das novas tecnologias de forma mais aguda e radical do que países considerados desenvolvidos. Novos processos de produção do conhecimento revolucionam os processos de difusão da informação, podendo "criar" um mundo virtual que convive em graus diferenciados de tensão/integração com o mundo real, transformando de modo radical o sentido do que venha a ser experiência. Os meios eletrônicos, ao mesmo tempo em que possibilitam a quase simultaneidade entre acontecimento e informação (o mundo é aqui e agora, em tempo real) "poupam" os indivíduos, intermediando vários de seus contatos com o mundo, protagonizando a potencialização do "encolhimento do mundo" Em certo sentido, seria o mundo virtual "construindo o 'real'". O outro lado desta mesma moeda transforma o real em espetáculo produzido pelos meios de massa. É o que ocorre, por exemplo, com o fenômeno da violência, transformado em produto, com amplo poder de venda no mercado de informação, e em objeto de consumo, fazendo com que a "realidade" da violência passe a fazer parte do dia-a-dia mesmo daqueles que nunca a confrontaram diretamente enquanto experiência de um processo vivido. A violência passa a ser consumida num movimento dinâmico em que o consumo participa também do processo de sua produção, ainda que como representação. Também como representação multiplicam-se as categorias de percepção da violência. Nesse sentido, é unânime a representação segundo a qual os meios funcionam como um tipo de tribunal do júri, antecipando ou dando o tom, em termos da condenação ou absolvição de um suspeito. 
Gráfico 2. "Os meios de comunicação de massa influenciam a opinião pública no julgamento de uma pessoa que cometeu determinado crime?"



Fonte: Pesquisa Sobre Representações Sociais da Violência no DF 1998.

A exposição à violência, da forma como é elaborada nas representações produzidas pela mídia, tem como uma de suas principais conseqüências transformar essa mesma violência em algo irreal, simulacral, espectro da realidade. Como aponta Michaud (1989, p. 51),

a realidade da violência não é estética: as fotografias do local de um atentado dão uma pálida idéia da náusea provocada por restos humanos despedaçados e pelo sangue em poças ou salpicado nas paredes. A fraqueza das imagens se deve a várias razôes: à censura corrente que descarta os documentos mais insustentáveis, à perda de definição resultante da reprodução mecânica, à estilização que encena artisticamente as imagens e as transforma em clichês, à banalização induzida pela repetição.

E, conclui o autor, se "a experiência contemporânea da violência passa pelas imagens, tal experiência só pode ser suavizada e banalizada" (1989, p. 51). Para alguns analistas, há "a possibilidade de que essa violência virtual tenha um sentido apaziguador, de conforto para as pessoas, porque se lidaria com a violência em um campo absolutamente abstrato" (Revista Atrator Estranho 5, 1994). 
A revolução científico-tecnológica pode ser vista, em alguma medida, como processo de democratização da informação. Ainda que os recursos da informática tenham consumo restrito e que o controle dos meios seja igualmente restrito à esfera privada, os meios de comunicação ditos de massa detêm uma performance multiplicadora. No caso da violência, como, de resto, de outros fenômenos contemporâneos, a velocidade do consumo tecnológico da informação, aliada ao processo político de re-democratização vivido pela sociedade brasileira, é sinônimo de maior visibilidade do fenômeno que, em conseqüência da democratização, articula-se a um movimento amplo de reivindicação do Estado de Direito enquanto condição de igualdade na cidadania. No nível jurídico, isso significa a reivindicação de procedimentos menos particularistas, mais conforme ao apelo por normas mais universalistas, características da modernidade. Mesmo que se admita que estes são processos ainda incipientes, sem poder para reverter o caráter de hierarquização das relações sociais enquanto traço dramaticamente característico da cultura brasileira, seu significado para a reconstrução institucional não parece desprezível. Outra conseqüência do mesmo processo é uma sociedade muito mais exigente, porque mais informada, com uma postura muito mais enérgica face ao fenômeno da impunidade, com uma propensão a nomear e a reconhecer a violência como violência, a recusar legitimidade a essa violência enquanto forma de estruturação social, como se pode depreender da pesquisa realizada (Porto, 2000). Este é um aspecto muitas vezes minimizado e que, no entanto, cumpre, em minha avaliação, importante papel no que concerne ao grau de politização da sociedade.

As reflexões contidas neste texto não têm intenção alguma de exagerar ou supervalorizar o papel da mídia e a função que as tecnologias, em particular os meios de massa, desempenham nas sociedades contemporâneas. Nessas sociedades, a comunicação e a informação estão organizadas empresarialmente, com as conseqüências daí decorrentes, em termos de mercado. A violência é, assim, uma moeda com alto poder de troca, porque uma mercadoria que vende e vende bem. 
Esta parece ser a opinião da maioria dos respondentes ao questionário, independentemente da situação socioeconômica, do nível de escolaridade ou da idade, sintonizando o senso comum às teorias que apontam que os meios de massa se alimentam do extraordinário.

Gráfico 3. "Na sua opinião, notícias sobre violência ajudam a vender jornais?"



Fonte: Pesquisa Sobre Representações Sociais da Violência no DF 1998.

Recorrendo mais uma vez a Michaud (1989, p. 49),

o fato de a violência se apresentar como uma crise em relação ao estado normal cria, por princípio, uma afinidade entre ela e a mídia. Como podemos constatar, num dia calmamente banal fica difícil fazer um jornal ou um noticiário de TV para anunciar que não aconteceu nada (...). A violência, com a carga de ruptura que ela veicula, é por princípio um alimento privilegiado para a mídia, com vantagem para as violências espetaculares, sangrentas ou atrozes sobre as violências comuns, banais e instaladas. 
Tabela 4.

\begin{tabular}{|c|c|c|c|c|c|}
\hline & \multicolumn{3}{|c|}{$\begin{array}{l}\text { "Na sua opinião, notícias sobre } \\
\text { violência ajudam a vender jornais?" }\end{array}$} & \multirow[b]{2}{*}{ Total } \\
\hline & & $\operatorname{sim}$ & não & $\begin{array}{l}\text { sem } \\
\text { ligação }\end{array}$ & \\
\hline \multirow[t]{3}{*}{ Escolaridade } & até $1^{\circ}$ grau & $84,3 \%$ & $11,3 \%$ & $4,4 \%$ & $100,0 \%$ \\
\hline & até $2^{\circ}$ grau & $85,5 \%$ & $9,3 \%$ & $5,2 \%$ & $100,0 \%$ \\
\hline & superior & $93,9 \%$ & $3,5 \%$ & $2,6 \%$ & $100,0 \%$ \\
\hline \multicolumn{2}{|l|}{ Total } & $86,6 \%$ & $9,0 \%$ & $4,4 \%$ & $100,0 \%$ \\
\hline
\end{tabular}

Fonte: Pesquisa Sobre Representações Sociais da Violência no DF 1998

Este é um lado da moeda. O outro aponta o fato de que esta estratégia da mídia responde, em última análise, a expectativas da sociedade. Como dizem os teóricos da comunicação, os meios de massa editam o imaginário popular. E, ao fazê-lo, contribuem para a constituição do fenômeno. Sob esse aspecto, é sintomático que 54,0\% dos respondentes do questionário não estejam, em sua maioria, dispostos a desligar seus apareIhos de TV em função de cenas violentas, como indica o gráfico abaixo.

Gráfico 4. "A existência de cenas de violência na TV é motivo suficiente para que você mude de canal ou desligue o seu aparelho?"

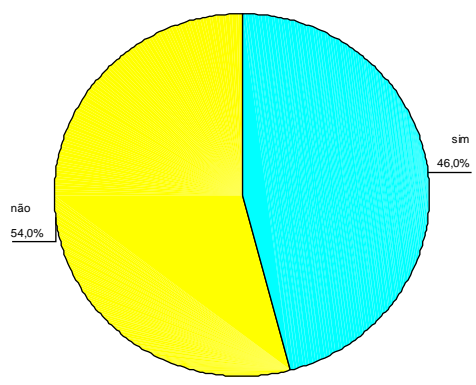

Fonte: Pesquisa sobre Representações Sociais da Violência no DF, 1998. 
O cruzamento dos dados traz alguma luz sobre os resultados. Os jovens estão mais propensos a permanecer assistindo à programação de um canal que transmite cenas violentas do que as demais faixas etárias, conforme aponta a Tabela 5.

Tabela 5.

\begin{tabular}{|c|c|c|c|c|}
\hline & \multicolumn{2}{|c|}{$\begin{array}{c}\text { "A existência de cenas de violência } \\
\text { na TV é motivo suficiente para que } \\
\text { você mude de canal ou desligue o seu } \\
\text { aparelho?" }\end{array}$} & \multirow[b]{2}{*}{ Total } \\
\hline & & $\operatorname{sim}$ & não & \\
\hline \multirow[t]{3}{*}{ Idade } & 15 a 24 & $35,9 \%$ & $64,1 \%$ & $100,0 \%$ \\
\hline & 25 a 44 & $46,7 \%$ & $53,3 \%$ & $100,0 \%$ \\
\hline & acima de 45 & $59,4 \%$ & $40,6 \%$ & $100,0 \%$ \\
\hline Total & & $46,0 \%$ & $54,0 \%$ & $100,0 \%$ \\
\hline
\end{tabular}

Fonte: Pesquisa sobre Representações Sociais da Violência, DF, 1998.

Tabela 6.

\begin{tabular}{|c|c|c|c|c|}
\hline & & \multicolumn{2}{|c|}{$\begin{array}{c}\text { "A existência de cenas de violência } \\
\text { na TV é motivo suficiente para que } \\
\text { você mude de canal ou desligue o } \\
\text { seu aparelho?" }\end{array}$} & \multirow[b]{2}{*}{ Total } \\
\hline & & $\operatorname{sim}$ & não & \\
\hline \multirow{3}{*}{$\begin{array}{l}\text { Camada } \\
\text { social }\end{array}$} & baixa & $44,4 \%$ & $55,6 \%$ & $100,0 \%$ \\
\hline & média & $49,8 \%$ & $50,2 \%$ & $100,0 \%$ \\
\hline & alta & $42,5 \%$ & $57,5 \%$ & $100,0 \%$ \\
\hline Total & & $46,0 \%$ & $54,0 \%$ & $100,0 \%$ \\
\hline
\end{tabular}

Fonte: Pesquisa sobre Representações Sociais da Violência, DF, 1998. 
Tabela 7.

\begin{tabular}{|c|c|c|c|c|}
\hline & \multicolumn{2}{|c|}{$\begin{array}{l}\text { "A existência de cenas de violência } \\
\text { na TV é motivo suficiente para que } \\
\text { você mude de canal ou desligue o } \\
\text { seu aparelho?" }\end{array}$} & \multirow[b]{2}{*}{ Total } \\
\hline & & $\operatorname{sim}$ & não & \\
\hline \multirow[t]{3}{*}{ Escolaridade } & até $1^{\circ}$ grau & $49,8 \%$ & $50,2 \%$ & $100,0 \%$ \\
\hline & até $2^{\circ}$ grau & $45,3 \%$ & $54,7 \%$ & $100,0 \%$ \\
\hline & superior & $39,7 \%$ & $60,3 \%$ & $100,0 \%$ \\
\hline Total & & $46,1 \%$ & $53,9 \%$ & $100,0 \%$ \\
\hline
\end{tabular}

Fonte: Pesquisa sobre Representações Sociais da Violência, DF, 1998.

As tabelas 6 e 7 apontam a complexidade e a ambigüidade dos discursos como representação. Expressão da ambigüidade e equivocidade da própria linguagem. É possível que a resistência a desligar a TV ou a mudar de canal em presença de cenas de violência, afirmada por $60,0 \%$ dos mais instruídos e escolarizados (e por 54,0\% dos respondentes das camadas mais favorecidas), explique-se pela crença de que a resposta positiva seria sinônimo de uma possível tendência a acatar qualquer tipo de censura. Essa explicação é tanto mais plausível quando se sabe que inúmeras pesquisas de opinião e de mercado têm mostrado que programas com conteúdos violentos encontram aceitação junto a faixas de renda mais baixas e menos instruídas.

Como se tentou alertar ao longo da exposição, a violência é um fenômeno plural. Não cabe, portanto, pensar suas causas no singular, atribuindoas apenas à midia. São múltiplas as causas das violências presentes na contemporaneidade brasileira, não podendo ser explicadas de modo unilateral por nenhuma das dimensões da vida social. Como analisamos em trabalho anterior (Porto, 2000), há uma conjugação de fatores atuando como causas da violência. Atribuir ao nível socioeconômico, político ou cultural de modo isolado a responsabilidade pela violência é simplificar a questão. Longe de pretender, com esta afirmação, minimizar a atuação dos meios de comunicação de massa, busca-se inseri-la no contexto maior das transformações que caracterizam a sociedade brasileira hoje, conforme explicitado no início desta análise. Nesse sentido, é na natureza da organização social e de suas configu- 
rações, transformações, continuidades e rupturas que se devem pesquisar as causas da violência. Essas transformações potencializam a fragmentação de valores, configurando um processo de dissolução de normas e de pontos fixos de referência que unificariam o olhar sobre a sociedade. A violência deve, assim, ser identificada de forma múltipla, diferenciada, e não pode ser analisada independentemente do campo social no qual se insere. Se muda a natureza do campo social mudam igualmente as formas de manifestação da violência, decorrência da ausência de pontos fixos de referência e da possibilidade de existência de múltiplos arranjos societários. Sob esse prisma, importa, por exemplo, refletir cuidadosamente sobre a contribuição da mídia no processo de conhecimento e na confecção de novas sociabilidades, conformadas na e pela violência. Sem pretender minimizar as implicações decorrentes das íntimas relações entre mídia e violência, deve-se atentar para a complexidade da questão, que não comporta nenhuma solução de caráter reducionista.

Todas estas questões remetem a uma última que é de natureza ética. A consideração do conteúdo ético dos meios de comunicação de massa não pode ser ignorada: suas implicações situam-se no âmbito da esfera pública, cuja ação deve fazer-se sentir junto às esferas estatal e privada, com o objetivo de elaboração de uma legislação conseqüente e responsável.

\section{Referências}

DURKHEIM, E. A divisão do trabalho social. Lisboa: Editorial Presença, 1984. GIDDENS, A. As conseqüências da modernidade. São Paulo: Ed. UNESP, 1991. MACHADO, L. A. Trabalhadores do Brasil: virem-se. Rio de Janeiro: Mimeo, 1999.

MACHADO, L. A. Criminalidade violenta e ordem pública: nota metodológica. Brasília, VIII Congresso da Sociedade Brasileira de Sociologia, 1997.

MICHAUD, Y. A violência. São Paulo: Ed. Ática, 1989. 
MICHAUD, Y. Violence et politique. Paris: Gallimard, 1988.

MICHAUD, Y. La violence apprivoisée. Paris: Hachette, 1996.

PORTO, M. S. G. Novas sociabilidades urbanas. Seminário Projeto SOL. Brasília, 1999.

PORTO, M.S.G. A violência entre a inclusão e a exclusão social. In: Tempo Social. Revista de Sociologia da USP, v. 12, n. 1, São Paulo, maio de 2000.

PORTO, M. S. G. Apresentação ao vol. X, n. 2, da revista Sociedade e Estado, Revista do Departamento de Sociologia da UnB, 1995.

ROCHA, R. L. M. Estética da Violência. In: Atrator Estranho, 5, fev. 1994.

TAVARES, J. V. T. (Org). Violência em tempos de globalização. São Paulo: Hucitec, 1999.

ZANOTTA, L. M. Um choque de violência ao vivo na TV. In: $<$ www.temporeal.com.br $>$.

\section{Resumo}

O artigo faz uma breve consideração inicial sobre os conceitos tratados, conforme aparecem no título, e, baseando-se em resultados de pesquisa, se detém na análise dos meios de massa enquanto variável causal na produção da violência contemporânea. Reconhecendo a existência de estreitas relações entre mídia e violência, enfatiza o caráter plural do fenômeno e de suas causas, apontando para os riscos de se diabolizar o papel da mídia responsabilizando-a, de modo unilateral pela produção e/ou crescimento da violência.

Palavras-chave: violência, mídia, contemporaneidade brasileira, Distrito Federal. 